Article

\title{
A New Wind Power Accommodation Strategy for Combined Heat and Power System Based on Bi-Directional Conversion
}

\author{
Yanhong Luo *, Zhenxing Yin, Dongsheng Yang and Bowen Zhou ${ }^{\mathbb{D}}$ \\ Department of Electric Engineering, Northeastern University, Shenyang 110004, China \\ * Correspondence: luoyanhong@ise.neu.edu.cn; Tel.: +86-138-9819-5450
}

Received: 31 May 2019; Accepted: 25 June 2019; Published: 26 June 2019

check for updates

\begin{abstract}
The extensive use of wind power can not only reduce dependence on fossil fuels, but also reduce emissions of polluted gases. However, large-scale wind power curtailments often occur in northeast China during the heat supply season, due to the fact that most of electrical demand is covered by the electrical power of the combined heat and power (CHP) during the off-peak hours. At present, for northeast China with heating demand, most of the research only focuses on how to accommodate more wind power on the spot by using one-directional conversion of the electric and thermal energy. But it is still difficult to realize the bi-directional conversion between the electro-gas or electro-thermal energy. In this paper, a combined electro-gas bi-directional conversion system (CEGBCS) is established by adding the power to gas (P2G), fuel cell and heat storage device in CHP system. This CEGBCS can not only realize bi-directional conversion of the electricity and gas, but also decouple the two operation modes of CHP unit, which greatly improve the ability of system to accommodate additional wind power. Finally, the effectiveness of the proposed CEGBCS is verified by comparing with two traditional methods.
\end{abstract}

Keywords: Combined heat and power (CHP); Bi-directional conversion; Wind power curtailments; Combined electro-gas bidirectional conversion system (CEGBCS); power to gas (P2G)

\section{Introduction}

Due to the uncertainty and volatility of wind power, it is impossible to be directly connected to the grid in a large scale at present [1,2]. The phenomenon of wind power curtailments often occurs in China, especially in the northeast China, where the accommodation of wind power is limited since the electric power of the combined heat and power (CHP) is enough for the electric load demand during most off-peak hour [3]. According to the national wind power statistics, the amount of wind power curtailments in China in the first half of 2017 is as high as $2.35 \times 10^{11} \mathrm{~kW} \cdot \mathrm{h}$, causing direct economic losses more than $1.8 \times 10^{10}$ yuan [4].

At present, there are mainly three methods to increase the wind power accommodation $[5,6]$ : (1) Direct storage of wind power using batteries [7-10]; (2) Expanding the capacity of the power grid; (3) Converting remaining wind power of system into other types of energy, such as pumped storage method [11,12], heat storage method, and gas storage method. In Reference [13], the cooperative operation of electric boiler and thermal power plant is used to improve the system's ability to accommodate wind power. A scheduling model based on CHP, heat storage device, and demand response is proposed in Reference [14]. To further increase the ability to accommodate wind power, the coordinating operation method is proposed among the heat storage device, CHP unit, heat storage device, or pumping energy storage in References [15,16]. The research in Reference [17] shows that by adding electric boiler and heat storage device into the CHP system, the operation of the CHP system 
is more flexible. In Reference [18], by adding electric boilers and heat pumps to the central heating system, the ability to accommodate wind power is improved.

In brief, above mentioned methods mainly improve the wind power accommodation in two ways: (1) Accommodating excess wind power in the system by converting the electric energy into storable thermal energy. (2) Decoupling the "Following the thermal load" mode of CHP units to improve the ability to accommodate wind power. However, these methods make it difficult to realize bi-directional conversion between the electro-gas or electro-thermal energy. Furthermore, even if the excess wind power is converted into thermal energy, it is difficult to store the thermal energy for a long time. Therefore, it is necessary to find another way or device to store the excess energy.

On the other hand, the emissions of polluted gases and energy purchase cost also play an important role for the operation of CHP systems. Therefore, in this paper, we establish a combined electro-gas bidirectional conversion system (CEGBCS) containing P2G, fuel cell, heat storage device, and CHP. This CEGBCS can not only promote the wind power accommodation, but also reduce the emissions of polluted gases and energy purchase cost. Totally, the contributions of this paper are as follows:

- Decouple two operating modes of CHP units simultaneously, i.e., "Following the Electric Load" and "Following the Thermal Load", which further improve the ability to accommodate wind power.

- Realize electro-gas bidirectional conversion (wind power to gas to electricity) by P2G and fuel cell, which can realize indirect power supply of wind power across time scales.

- $\quad$ Store the large-scale excess wind power, i.e., the wind power which cannot be used by electric load, in the form of gas by using P2G technology. When the user needs electrical energy or thermal energy, the gas produced by $\mathrm{P} 2 \mathrm{G}$ is used to generate power.

The paper is structured as follows: In Section 2, the operating characteristics of power to gas (P2G) and proton exchange membrane fuel cell (PEMFC) in CEGBCS are introduced. The dual-mode decoupling of CEGBCS and its wind power accommodation strategy are described in detail in Section 3. The coordinated optimal scheduling of CEGBS is provided in Section 4, and the case study is presented in Section 5. Finally, the conclusions are drawn in Section 6.

\section{Operation Characteristics of Internal Devices in Combined Electro-Gas Bi-Directional Conversion System (CEGBCS)}

The following part mainly introduces the operating characteristics of the power to gas and proton exchange membrane fuel cell in CEGBCS.

\subsection{Operating Characteristics of Power to Gas}

According to the type of gas that is eventually produced, power to gas (P2G) can be divided into two main categories $[19,20]$ : electric methane production (electric natural gas production) and electric hydrogen production. Both the technologies have their own advantages and disadvantages, and detail information can be found in Reference [21]. In this paper, the P2G used in CEGBCS is electric methane production, whose core principle is composed of two parts [22,23]. Firstly, hydrogen and oxygen are produced by electrolytic water. Then, under the action of catalyst, the hydrogen obtained by electrolytic water and $\mathrm{CO}_{2}$ pass through "Sabatier Reaction" to obtain $\mathrm{CH}_{4}$ and $\mathrm{H}_{2} \mathrm{O}$. Here, "Sabatier Reaction" is used to denote the chemical reaction in which $\mathrm{CO}_{2}$ is hydrogenated. This reaction can occur chemically with a catalyst or biochemically with archaea. In this paper, the term of "Sabatier Reaction" refers to chemical reaction.

The methane produced by this reaction is called "Renewable Power Methane (RPM)" [24]. The working principle is shown in Figure 1. 


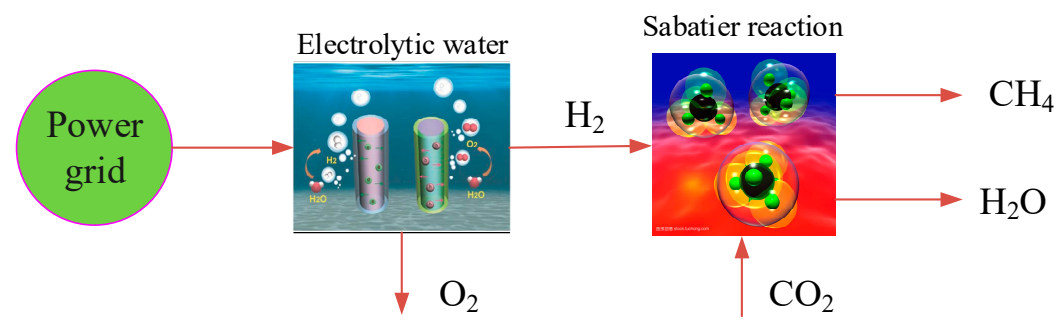

Figure 1. Production process of power to gas.

P2G technology can transform the excess electricity of system into methane and store it in the natural gas pipeline network. When the system needs electricity, it supplies gas turbines and fuel cells for power generation. P2G not only provides a new way for indirect storage of electric energy, but also increases the system's ability of wind power accommodation. At present, the conversion efficiency of P2G technology can reach 60-70\% [25].

\subsection{Operating Characteristics of Proton Exchange Membrane Fuel Cells}

Fuel cell is a device that produces electric energy by chemical reaction under hydrogen containing fuel and oxidant [26]. The fuel cell used in this paper is a Proton Exchange Membrane Fuel Cells (PEMFC) $[27,28]$. It uses natural gas as fuel, and its chemical reaction equation is as shown in formula (1).

$$
\mathrm{CH}_{4}+2 \mathrm{H}_{2} \mathrm{O} \rightarrow 4 \mathrm{H}_{2}+\mathrm{CO}_{2}
$$

Fuel cell is a controllable power generation equipment. It can be used to regulate the power and enhance the response speed of the system. At present, the conversion efficiency of PEMFC is over $60 \%$ [29].

\section{Dual-Mode Decoupling of Combined Electro-Gas Bi-Directional Conversion System (CEGBCS) and Wind Power Accommodation Strategy}

The CEGBCS proposed in this paper is as shown in Figure 2. It consists of P2G, fuel cell, heat storage device, and CHP unit. The reason for decoupling the relationship of the electric power and thermal power of CHP units is to further improve the system's ability to accommodate wind power. The following part will introduce how to decouple two modes of CHP unit by CEGBCS and further present the wind power accommodation strategy.

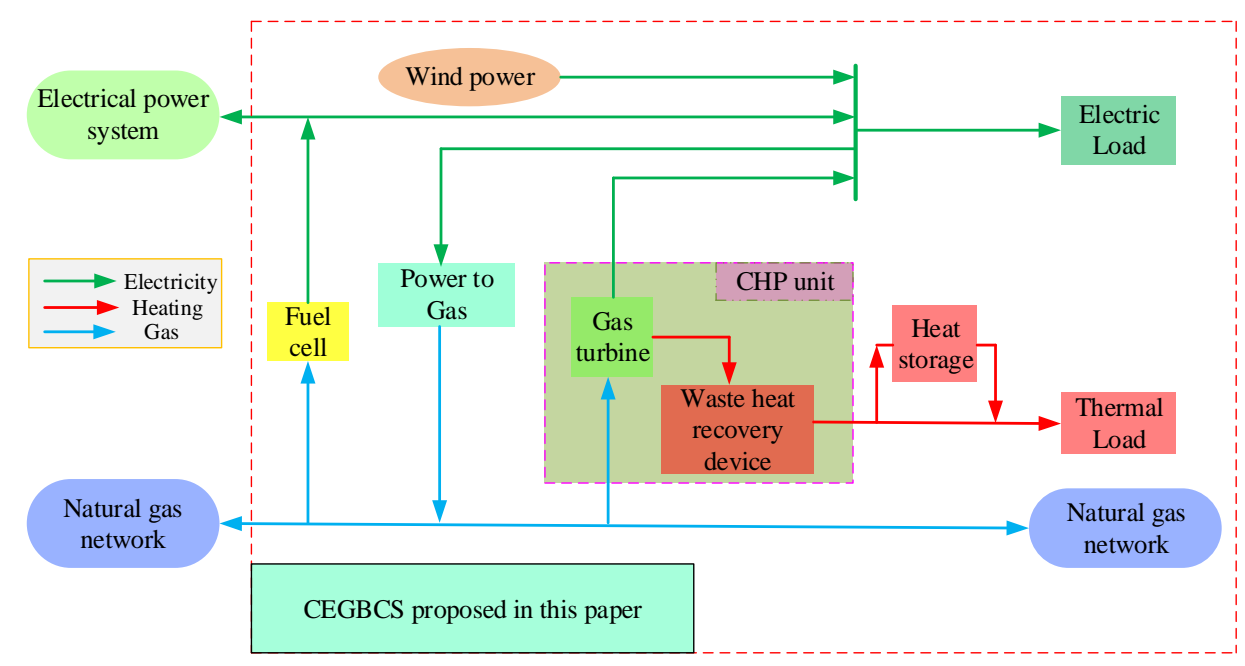

Figure 2. Composition of gas-electric bidirectional conversion system. 
3.1. Decoupling Principle of Combined Heat and Power (CHP) for the Mode of "Following the Thermal Load"

The mode of "Following the Thermal Load" (FTL) of CHP means that the operating status of CHP is determined by thermal load. In other words, CHP preferentially meets thermal load demand, and the system unconditionally accepts the produced electric energy.

In this paper, the principle for decoupling the FTL mode by CEGBS is shown in Figure 3.

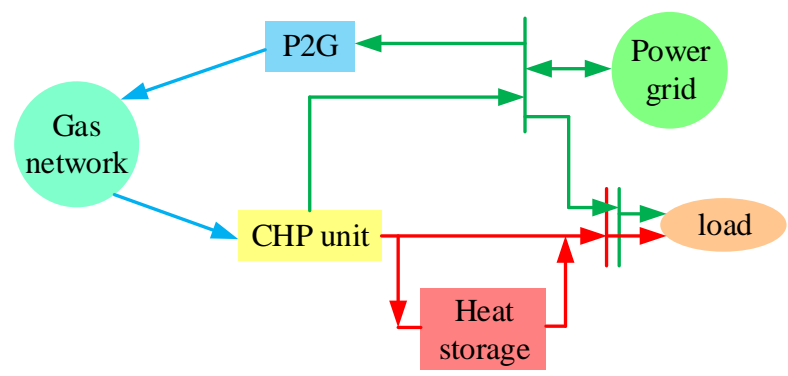

Figure 3. Principle of decoupling the mode of FTL.

In order to meet the users' thermal demand firstly, CHP unit operates in the mode of "Following the Thermal load". The excess electric power generated by CHP unit, i.e., the power which cannot be consumed by user or connected to gird, could be consumed by P2G. Therefore, the excess power will not affect the electrical load side. When the demand for heat load is low and the demand for electricity load is high, the CHP unit generates as much electric energy as possible within its economic scope, and the excess heat energy generated by $\mathrm{CHP}$ is stored in the heat storage device. Thus, the excess thermal energy will not affect the thermal load, either.

\subsection{Decoupling Principle of Combined Heat and Power (CHP) for the Mode of "Following the Electric Load"}

The mode of "Following the Electric Load" (FEL) of CHP means that the operating status of CHP is determined by electric load. In other words, CHP preferentially meets electric load demand, and the system unconditionally accepts the produced thermal energy.

In this paper, the principle for decoupling the FEL mode of CHP is shown in Figure 4.

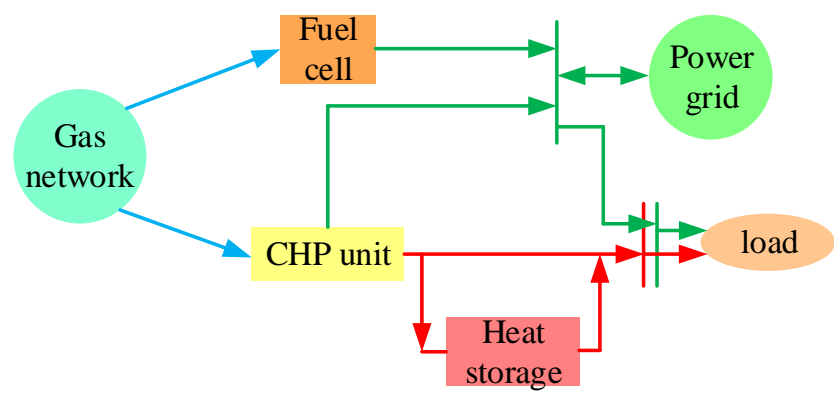

Figure 4. Principle of decoupling mode of Following the Electric Load (FEL).

In order to meet the users' electric demand firstly, CHP unit operates in the mode of "Following the Electric Load". When the heat storage device reaches full storage, the excessive electric demand in the system can be satisfied by increasing the fuel cell output, thereby avoiding the impact of excessive thermal energy on user's comfort. Furthermore, the capacity of the heat storage device can be reduced, which can decrease the cost in some extent.

\subsection{Wind Power Accommodation Strategy}

When the intermittent renewable energy is accommodated or dispatched, the corresponding control strategies need to be proposed $[30,31]$. The CEGBCS proposed in this paper is to improve the 
ability of the system to accommodate wind power from two aspects. Firstly, based on the structure of system, the ability of the system to accommodate wind power is improved by decoupling the relationship of the electric power and thermal power of CHP units, which can increase the flexibility of system. Secondly, from the aspect of optimal scheduling, by minimizing the objective function composed of the energy purchase cost and pollution gas treatment cost, the electric load in the system will preferentially accommodate wind power of system. Then, the remaining wind power is transformed into storable natural gas by using P2G technology. Figure 5 shows how CEGBCS accommodates wind power by optimal scheduling method.

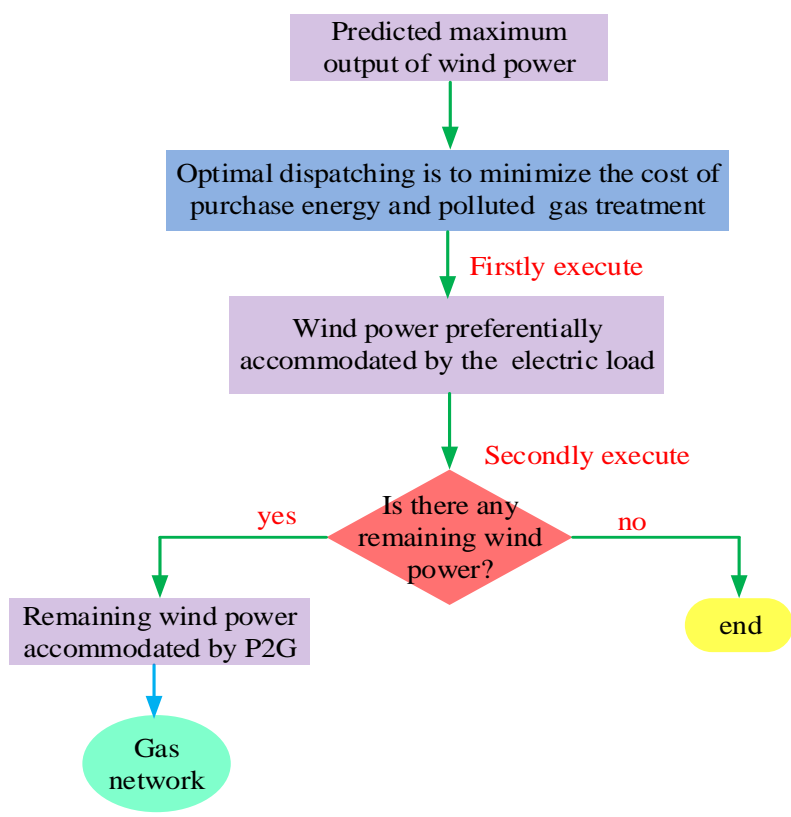

Figure 5. Combined Electro-Gas Bi-Directional Conversion System (CEGBCS) accommodate wind power by optimization.

\section{Coordinated Optimal Scheduling of Combined Electro-Gas Bi-Directional Conversion System (CEGBS)}

\subsection{Mathematical Modeling of Combined Electro-Gas Bi-Directional Conversion System (CEGBS)} Internal Devices

\subsubsection{Combined Heat and Power (CHP) Unit Model}

In this paper, the CHP unit is composed of a gas turbine and waste heat recovery device. The relationship between the output electric power and thermal power of the gas turbine is as follows:

$$
\begin{gathered}
P_{g e}^{C H P}=\eta_{g e}^{C H P} \cdot F_{g a s}^{C H P} \cdot L_{V} \\
Q_{g h}^{C H P}=\left(1-\eta_{g e}^{C H P}-\eta_{\text {loss }}^{C H P}\right) \cdot F_{g a s}^{C H P} \cdot L_{V}=P_{g e}^{C H P} \cdot V_{C H P}
\end{gathered}
$$

where, $P_{g e}^{C H P}$ and $Q_{g h}^{C H P}$ represent the output electric power and thermal power of gas turbine respectively $(\mathrm{kW}) ; \eta_{g e}^{\mathrm{CHP}}$ and $\eta_{\text {loss }}^{\mathrm{CHP}}$ are the power generation efficiency and energy loss of gas turbine respectively; $F_{\text {gas }}^{C H P}, L_{V}$ and $V_{C H P}$ are the amount of natural gas consumed by the gas turbine $\left(\mathrm{m}^{3}\right)$, the low calorific value of natural gas $\left(\mathrm{kWh} / \mathrm{m}^{3}\right)$, and the thermoelectric ratio of the gas turbine respectively.

The heat energy recovered by waste heat recovery device is as follows:

$$
Q_{H B}=Q_{g h}^{C H P} \cdot \eta_{H B}
$$


where, $Q_{H B}$ is the thermal power output of the waste heat recovery device $(\mathrm{kW}) ; \eta_{H B}$ is the conversion efficiency of waste heat recovery device.

\subsubsection{Power to Gas (P2G)}

The relationship between the produced natural gas and the consumed electric power for P2G is as follows:

$$
V_{g a s}^{P 2 G}=\eta_{g a s}^{P 2 G} \cdot P_{e}^{P 2 G} / L_{V}
$$

where, $V_{g a s}^{P 2 G}$ is the gas produced by the P2G $\left(\mathrm{m}^{3}\right) ; \eta_{g a s}^{P 2 G}$ is the conversion efficiency of P2G; $P_{e}^{P 2 G}$ is electric energy consumed by P2G $(\mathrm{kW})$.

\subsubsection{Fuel Cell Model}

The fuel cell in this paper uses natural gas as fuel to generate electricity. The relationship between the produced electricity and the consumed natural gas is as follows:

$$
P_{F C}=\eta_{F C} \cdot V_{g a s}^{F C} \cdot L_{V}
$$

where, $V_{g a s}^{F C}$ is the gas consumed by the fuel cell $\left(\mathrm{m}^{3}\right) ; \eta_{F C}$ is the efficiency of fuel cell; $P_{F C}(\mathrm{~kW})$ is electric energy produced by fuel cell.

\subsubsection{Heat Storage Model}

Heat storage device stores thermal energy at time $t+1$ is related to the thermal energy at time $t$ and the thermal energy charge or release at time $t+1$. The formula of heat storage device is as follows:

$$
\begin{gathered}
W_{(t+1)}^{H S}=W_{(t)}^{H S} \cdot\left(1-\delta_{H S}\right)+Q_{h s . c}^{(t+1)} \cdot \eta_{h s . c} \cdot \Delta t \\
W_{(t+1)}^{H S}=W_{(t)}^{H S} \cdot\left(1-\delta_{H S}\right)-\frac{Q_{d s . c}^{(t+1)}}{\eta_{d s . c}} \cdot \Delta t
\end{gathered}
$$

where, $W_{(t+1)}^{H S}$ represents the storage of thermal energy of heat storage device at $t+1(\mathrm{kWh}) . W_{(t)}^{H S}(\mathrm{kWh})$ represents the storage of thermal energy of heat storage device at $t . \delta_{H S}$ is the heat loss rate of heat storage devices; $\eta_{h s . c}$ and $\eta_{d s . c}$ are the charging and discharging efficiency of heat storage device, respectively; $Q_{h s . c}^{(t+1)}$ and $Q_{d s . c}^{(t+1)}$ are the heat charge power and heat discharge power of the heat storage device, respectively.

\subsection{Coordinated Optimization Modeling of Combined Electro-Gas Bi-Directional Conversion System (CEGBS)}

\subsubsection{Objective Function of Optimal Scheduling}

In this paper, the objective is to minimize the energy purchase cost and environmental cost. The specific objective function is as follows:

$$
C_{f}=\min \left(C_{f 1}+C_{f 2}\right)
$$

where, $C_{f}$ is the total operating cost of system (yuan); $C_{f 1}$ is the system's energy purchase cost (yuan); $C_{f 2}$ is environmental costs (yuan).

1. System Energy Purchase Cost

The formula for calculating the cost of electricity purchase is as follows:

$$
C_{f 11}=\sum_{t=1}^{24}\left(c_{e c}^{t} \cdot P_{\text {grid }}^{t}\right) \Delta t
$$


where, $c_{e c}^{t}$ is the price of electricity purchased (or sold) at different times of a day (yuan $/ \mathrm{kWh}$ ); $P_{g \text { rid }}^{t}$ is the electric power purchased from grid at time $t(\mathrm{~kW})$.

The formula of gas purchase cost is as follows:

$$
C_{f 12}=c_{c g} \cdot \sum_{t=1}^{24}\left(F_{g a s . t}^{C H P}+V_{g a s . t}^{C F}-V_{g a s . t}^{P 2 G}\right)
$$

Substituting Equation (2), Equation (5), and Equation (6) into Equation (11), the gas purchase cost can be further obtained by:

$$
C_{f 12}=c_{c g} \cdot\left[\sum_{t=1}^{24}\left(P_{g e . t}^{C H P} / \eta_{g e}^{C H P}+P_{t}^{C F} / \eta_{F C}-P_{e . t}^{P 2 G} \cdot \eta_{g a s}^{P 2 G}\right] / L_{V}\right.
$$

where, $c_{g c}$ is the price of natural gas $\left(2.5714\right.$ yuan $\left./ \mathrm{m}^{3}\right) . F_{\text {gas.t }}^{C H P}, V_{\text {gas.t }}^{C H P}$ and $V_{\text {gas.t }}^{P 2 G}$ are the natural gas consumed by gas turbines, the natural gas consumed by fuel cells, and the natural gas produced by $\mathrm{P} 2 \mathrm{G}$, respectively $\left(\mathrm{m}^{3}\right) . P_{\text {ge.t }}^{C H P}, P_{t}^{C F}$ and $P_{e . t}^{P 2 G}$ are the electric power output by the gas turbine, the electric power output by the fuel cell, and the wind power used by P2G at time $t$, respectively $(\mathrm{kW})$; $\eta_{g e}$, $\eta_{F C}$ and $\eta_{g a s}^{P 2 G}$ are conversion efficiency of gas turbine, fuel cell, and P2G, respectively.

According to Equation (11) and Equation (12), the cost of purchasing energy of the system is as follows:

$$
C_{f 1}=C_{f 11}+C_{f 12}
$$

\section{Environmental Cost}

The environmental cost is mainly the equivalent $\mathrm{CO}_{2}$ processing cost. It is mainly composed of three parts: equivalent $\mathrm{CO}_{2}$ emission from electricity purchase in distribution network, equivalent $\mathrm{CO}_{2}$ emission from gas purchase in gas network, and the equivalent $\mathrm{CO}_{2}$ absorption by $\mathrm{P} 2 \mathrm{G}$ [23]. The formula is as follows:

$$
C_{f 2}=\zeta \cdot \sum_{t=1}^{24}\left[\lambda_{c 0_{2}}^{e} \cdot P_{g r i d}^{t}+\lambda_{c 0_{2}}^{g} \cdot\left(\frac{P_{g e . t}^{C H P}}{\eta_{g e}^{C H P}}+\frac{P_{t}^{F C}}{\eta_{F C}}\right)-\lambda_{c 0_{2}}^{g} \cdot P_{e . t}^{P 2 G} \cdot \eta_{g a s}^{P 2 G}\right]
$$

where, $\zeta$ is the unit processing cost of $\mathrm{CO}_{2}$, (yuan/kg); $\lambda_{\mathrm{Co}_{2}}^{e}$ and $\lambda_{\mathrm{CO}_{2}}^{g}$ represent equivalent $\mathrm{CO}_{2}$ emission factors for electricity purchases and gas purchases $(\mathrm{kg} / \mathrm{kWh})$.

\subsubsection{Operational Constraints}

1. Equality Constrains

$$
\begin{gathered}
P_{\text {grid }}^{t}+P_{\text {wind.t }}^{\text {optimal }}+P_{\text {ge.t }}^{C H P}+P_{t}^{F C}-P_{\text {load.t }}=0 \\
P_{\text {wind.t }}^{\text {abandon }}-P_{e . t}^{P 2 G}=0 \\
P_{\text {wind.t }}^{\text {abandon }}+P_{\text {wind.t }}^{\text {optimal }}=P_{t}^{\text {wind }} \\
Q_{B H}^{t}+\delta_{t} \cdot Q_{d s . c}^{t}-\left(1-\delta_{t}\right) \cdot Q_{h s . c}^{t}-Q_{\text {load }}^{t}=0
\end{gathered}
$$

where, $P_{\text {wind.t }}^{\text {optimal }}$ is accommodated wind power by system's electric load through the optimal dispatching at time $\mathrm{t}(\mathrm{kW}) ; P_{\text {wind.t }}^{\text {abandon }}$ is the accommodated wind power by P2G at time $t(\mathrm{~kW}) ; P_{t}^{\text {wind }}$ is the total wind power consumption at time $\mathrm{t}(\mathrm{kW}) ; P_{g e . t}^{C H P}, P_{t}^{F C}$, and $P_{e . t}^{P 2 G}$ are the output power of the gas turbine, fuel cell, and P2G, respectively $(\mathrm{kW}) ; P_{\text {load.t }}$ is the electric load of system $(\mathrm{kW}) . Q_{B H^{\prime}}^{t} Q_{d s . c^{\prime}}^{t} Q_{h s . c^{\prime}}^{t}$ and $Q_{\text {load }}^{t}$ represent the thermal energy produced by the waste heat boiler, the thermal energy produced by the 
heat storage device, the thermal energy stored in the heat storage device, and the thermal energy required by user $(\mathrm{kW}) ; \delta_{t}$ is the variable which only equals 0 or 1 .

2. Inequality Constrains

$$
\begin{gathered}
P_{\text {grid }}^{\min }<=P_{\text {grid }}^{t}<=P_{\text {grid }}^{\max } \\
0<=P_{\text {ge.t }}^{C H P}<=P_{\text {ge.max }}^{C H P} \\
0<=Q_{H B}^{t}<=Q_{H B}^{\max } \\
0<=P_{e . t}^{P 2 G}<=P_{e . \max }^{P 2 G} \\
0<=P_{t}^{F C}<=P_{F C}^{\max } \\
0 \leq Q_{h s . c}^{t} \leq Q_{h s . c}^{\max } \\
0 \leq Q_{d s . c}^{t} \leq Q_{d s . c}^{\max } \\
W_{H S . m i n} \leq W_{H S}^{t} \leq W_{H S . m a x}
\end{gathered}
$$

where, $P_{\text {grid }}^{\min }$ and $P_{\text {grid }}^{\max }$ are the maximum constraints on feeding and purchasing power $(\mathrm{kW}) ; Q_{h s . c}^{\max }$ is the maximum heat storage power $(\mathrm{kW}) ; Q_{d s . c}^{\max }$ is the maximum heat release power $(\mathrm{kW}) ; W_{H S . m i n}$ and $W_{\text {HS.max }}$ represent the minimum and maximum heat storage, respectively(kWh).

\subsubsection{Solution Method}

At present, there are many methods to solve optimization problems, such as evolutionary algorithm [32] or numerical algorithm [33]. In this paper, we use Yalmip, which is a toolbox of MATLABR2014a to solve the optimization problem. Yalmip is a simple, practical, and efficient mathematical modeling tool, which can be invoked by MATLAB. After modeling the optimization problem with Yalmip, it will invoke the appropriate solver (such as, gurobi, cplex, fmincon, etc.) in MATLAB to solve the optimization problem. Fmincon is a solver in MATLAB, which is used in this paper to find the optimal solution.

In order to use Yalmip in Matlab, we first write the standard form of the model as follows [34]:

$$
\begin{cases}\min & C(x) \\ \text { s.t. } & A x=b \\ & x_{\min }<=x_{i}<=x_{\max } \quad i \in Z\end{cases}
$$

where, $C(x)$ is the objective function of optimal scheduling, which is represented by Equation (9). $x$ is the decision variable of optimization problem, which contains wind power accommodation, the active power output of the devices in the system, the charging and discharging of the heat storage device, and the purchase of electricity from the power grid. Equations (15) to (18) consist of the equality constraints. Inequality constraints are composed by Equations (19) to (26).

\section{Simulation Study}

In this section, the effectiveness of CEGBCS proposed in this paper is verified. Firstly, the simulation parameters, the time-sharing electricity price of a day, the typical daily thermoelectric load curve, and the maximum output prediction curve of wind power generation without restriction are given in Table 1 and Figures 6-8, respectively. Then, two traditional wind power accommodation methods are introduced in Scenarios 1-2, which are used to compare with the approach proposed in this paper. Finally, the effectiveness of the proposed method in accommodating wind power is verified by the simulation analysis. 
Table 1. Simulation Parameters.

\begin{tabular}{cccccccc}
\hline Parameter & Value & Parameter & Value & Parameter & Value & Parameter & Value \\
\hline$Q_{h s . c}^{\max }(\mathrm{kW})$ & 600 & $Q_{d s . c}^{\max }(\mathrm{kW})$ & 800 & $W_{H S . \min }(\mathrm{kW} \cdot \mathrm{h})$ & 400 & $W_{H S . m a x}(\mathrm{~kW} \cdot \mathrm{h})$ & 1000 \\
$\eta_{h s . c}$ & 0.98 & $\eta_{h s . d}$ & 0.98 & $\delta_{h s . c}$ & 0.002 & $P_{g e . m a x}^{C H P}(\mathrm{~kW})$ & 1000 \\
$\eta_{g e}^{C H P}$ & 0.3 & $V_{C H P}$ & 1.8 & $\eta_{\text {loss }}^{C H P}$ & 0.001 & $Q_{H B}^{\max }(\mathrm{kW})$ & 1500 \\
$\eta_{H B}$ & 0.89 & $\eta_{\text {gas }}^{P 2 G}$ & 0.7 & $\eta_{F C}$ & 0.65 & $P_{F C}^{\max }(\mathrm{kW})$ & 600 \\
$P_{\text {e.max }}^{P 2 G}(\mathrm{~kW})$ & 700 & $\xi(\mathrm{yuan} / \mathrm{kg})$ & 0.031 & $\lambda_{c 0_{2}}^{g}(\mathrm{~kg} /(\mathrm{kW} \cdot \mathrm{h}))$ & 0.23 & $\lambda_{c 0_{2}}^{e}(\mathrm{~kg} /(\mathrm{kW} \cdot \mathrm{h}))$ & 0.972 \\
$P_{\text {grid }}^{\max }(\mathrm{kW})$ & 1000 & $P_{\text {grid }}^{\min }(\mathrm{kW})$ & -200 & $L_{V}\left(\mathrm{kWh} / \mathrm{m}^{3}\right)$ & 9.89 & - & - \\
\hline
\end{tabular}

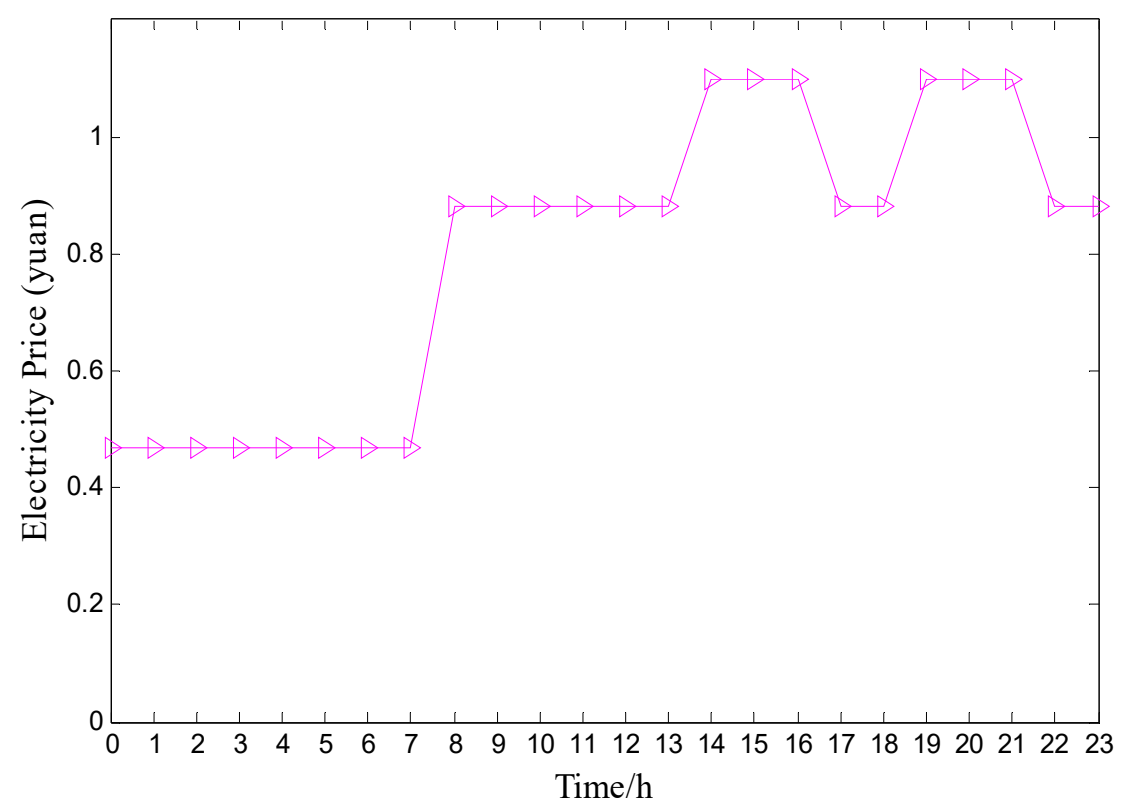

Figure 6. The time-sharing electricity price of a day.

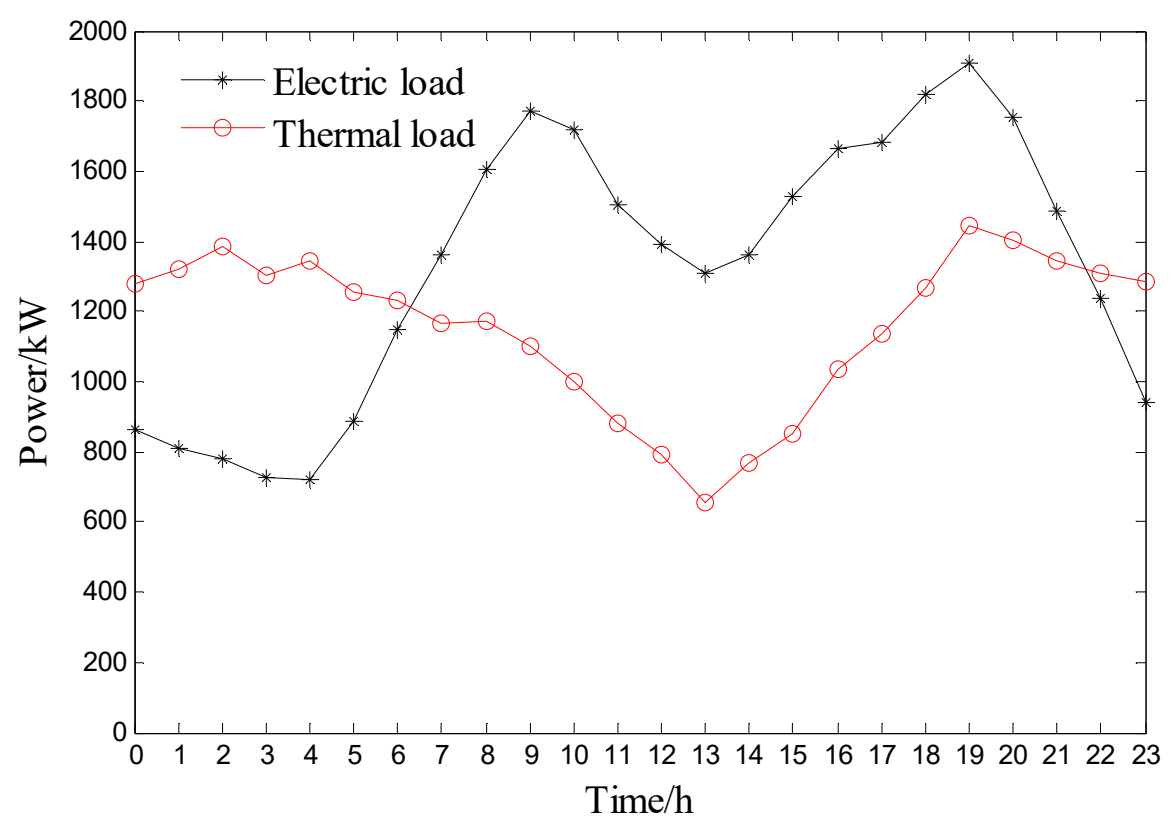

Figure 7. Typical daily thermoelectric load curve. 


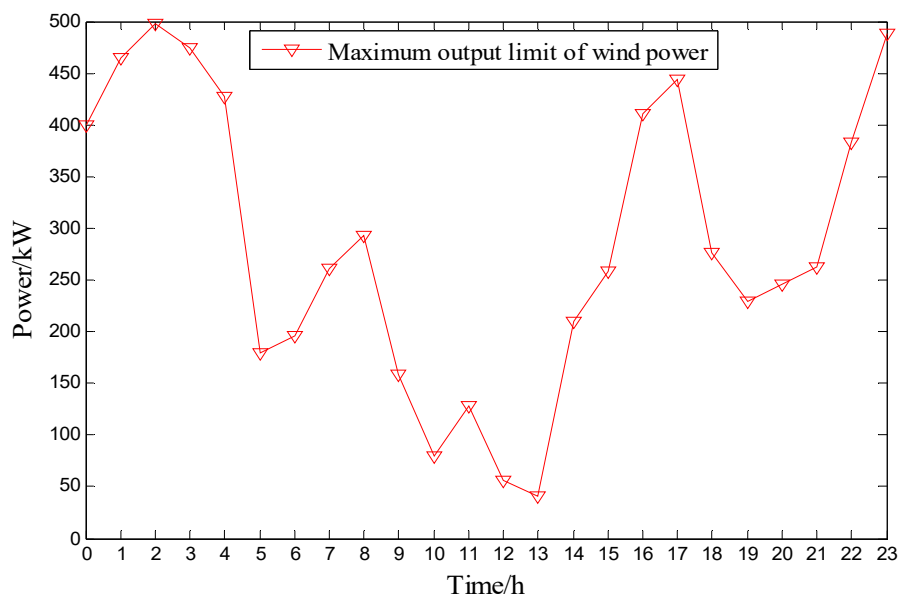

Figure 8. Maximum output prediction curve of wind power generation without restriction.

\subsection{Scenario Description}

In order to verify the effect of wind power accommodation, the CEGBCS proposed in this paper is compared with two traditional models [15,17].

Scenario 1: Only the thermal storage device is used in the CHP system (traditional model). Its structure diagram is shown in Figure 9;

Scenario 2: Both the electric boiler and thermal storage device are used in CHP system (traditional model). Its structure diagram is shown in Figure 10;

Scenario 3: The P2G, thermal storage device and fuel cell are used in CHP system (i.e., CEGBCS proposed in this paper). Its structure diagram is shown in Figure 2.

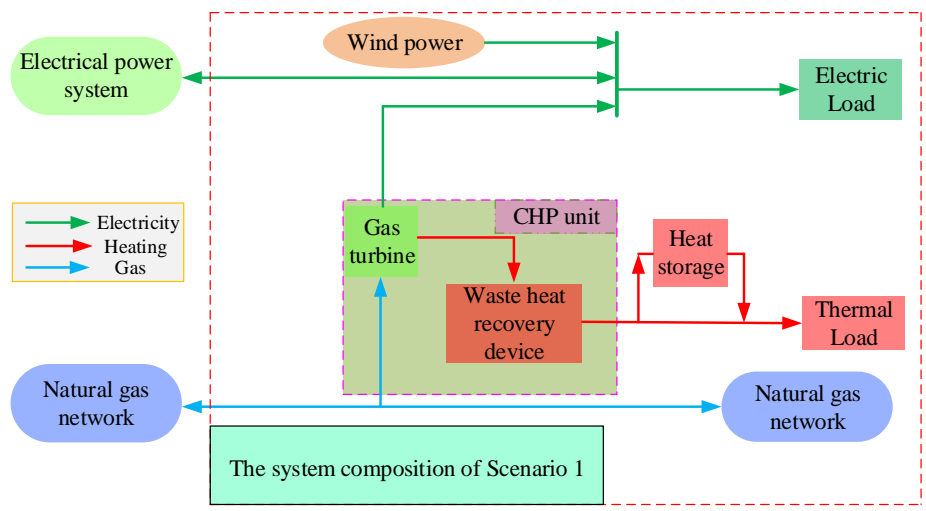

Figure 9. The structure diagram of Scenario 1.

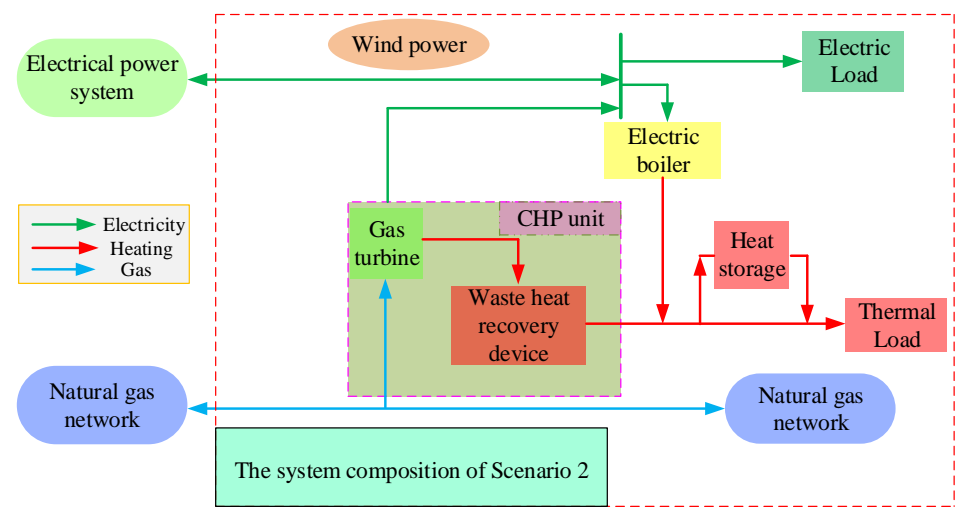

Figure 10. The structure diagram of Scenario 2. 
The detailed composition of each scenario is as shown in Table 2, where the symbol " $\sqrt{ }$ " means that the device is included in scenario, and the symbol " $X$ " indicates that the device is not included in the scenario. GT is gas turbine; HB is waste heat recovery device; FC is fuel cell; P2G is power to gas; EB is electric boiler; WT is wind turbine; HS is heat storage device. Maximum electric power of EB is $700 \mathrm{~kW}$, and efficiency of EB is 0.98 .

Table 2. Scenario classification.

\begin{tabular}{cccccccc}
\hline Scene & GT & HB & FC & P2G & EB & WT & HS \\
\hline Scenario 1 & $\sqrt{ }$ & $\sqrt{ }$ & $\times$ & $\times$ & $\times$ & $\sqrt{ }$ & $\sqrt{ }$ \\
Scenario 2 & $\sqrt{ }$ & $\sqrt{ }$ & $\times$ & $\times$ & $\sqrt{ }$ & $\sqrt{ }$ & $\sqrt{ }$ \\
Scenario 3 & $\sqrt{ }$ & $\sqrt{ }$ & $\sqrt{ }$ & $\sqrt{ }$ & $\times$ & $\sqrt{ }$ & $\sqrt{ }$ \\
\hline
\end{tabular}

\subsection{Simulation Result Analysis}

Table 3 and Figure 11 shows the comparison of wind power accommodation by the same electric load. As shown in Table 3, the total wind power accommodation by electric load in Scenario 1 is $3640.85 \mathrm{~kW}$, the total wind power accommodation by electric load in Scenario 2 is $4011.97 \mathrm{~kW}$, and the total wind power accommodation by electric load in Scenario 3 is $4278.58 \mathrm{~kW}$. This shows that the wind power accommodation by electric load in Scenario 3 is higher than other Scenarios. Meanwhile, the wind power accommodation by electric load in Scenario 3 is increased by $17.52 \%$ than Scenario 1, the wind power accommodation by electric load in Scenario 3 is increased by $6.65 \%$ than Scenario 2 .

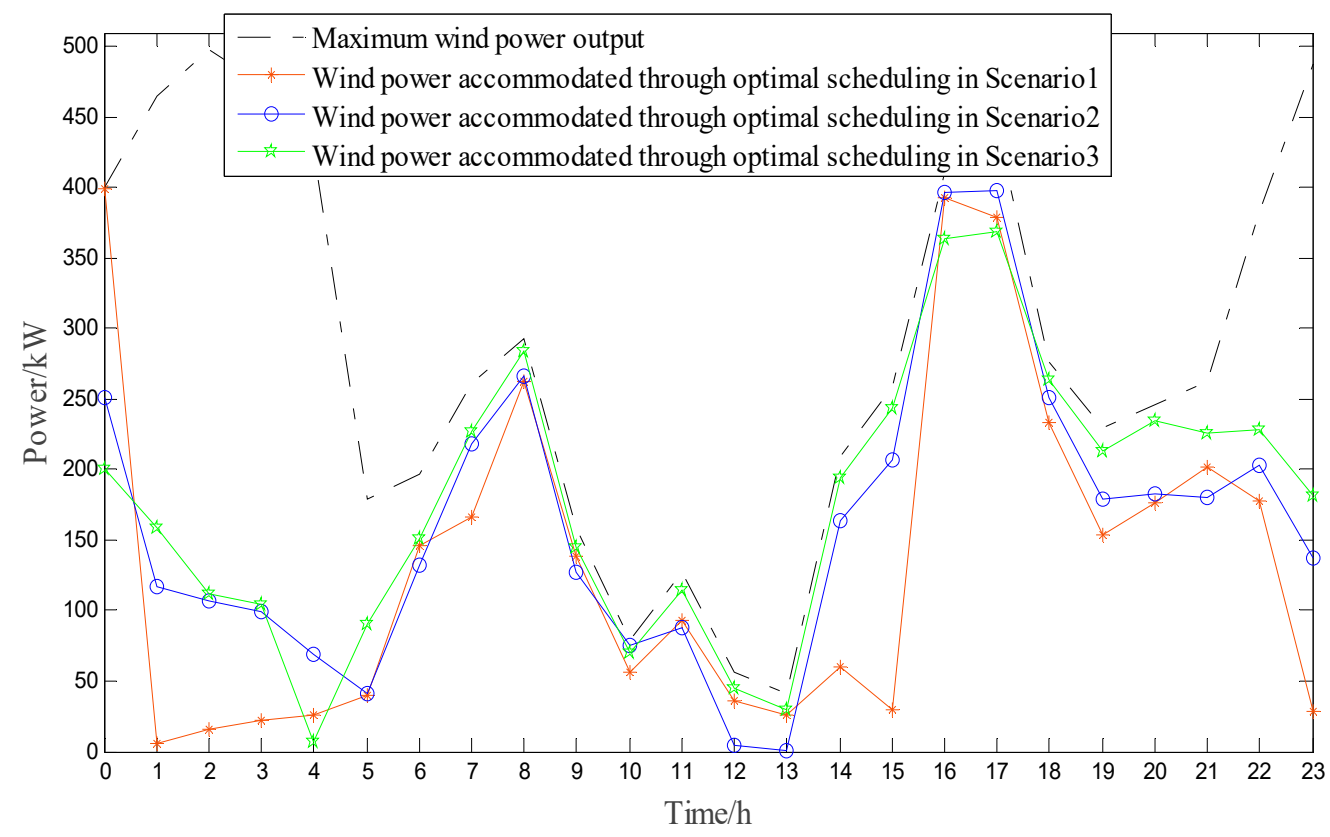

Figure 11. Wind power consumption by internal load of combined heat and power (CHP) system in different scenarios.

The optimal costs of different Scenarios are shown in Table 4. As shown in Table 4, although the cost of gas purchase in Scenario 3 is higher than Scenario 1 and Scenario 2, the cost of electricity purchase, environmental cost and total operation cost in Scenario 3 is less than other two scenarios. The total cost of scenario 3 is less due to two factors: (1) The wind power accommodation by electric load in scenario 3 is more than other two scenarios, and this leads to a reduction in electricity purchases from the grid. (2) When P2G accommodate excess wind power, a large amount of $\mathrm{CO}_{2}$ in the air is absorbed by $\mathrm{P} 2 \mathrm{G}$, thus the environment treatment cost is reduced. 
Table 3. Wind power accommodation by same electric load at different time (kW).

\begin{tabular}{cccccccc}
\hline Time/h & Scenario 1 & Scenario 2 & Scenario 3 & Time/h & Scenario 1 & Scenario 2 & Scenario 3 \\
\hline 0 & 399.82 & 251.60 & 200.30 & 12 & 92.59 & 87.65 & 114.96 \\
1 & 5.74 & 117.25 & 159.35 & 13 & 36.65 & 4.21 & 44.90 \\
2 & 15.23 & 107.12 & 112.35 & 14 & 25.34 & 0.22 & 29.95 \\
3 & 22.15 & 98.87 & 104.91 & 15 & 60.33 & 163.52 & 193.86 \\
4 & 26.56 & 69.32 & 6.38 & 16 & 29.59 & 207.46 & 243.55 \\
5 & 40.06 & 41.59 & 90.17 & 17 & 392.54 & 396.82 & 364.17 \\
6 & 146.36 & 132.04 & 151.77 & 18 & 379.32 & 398.13 & 369.49 \\
7 & 166.59 & 217.71 & 226.85 & 19 & 233.49 & 251.02 & 263.82 \\
8 & 263.22 & 266.75 & 284.13 & 20 & 154.25 & 179.45 & 213.81 \\
9 & 138.20 & 127.54 & 144.81 & 21 & 176.77 & 182.79 & 235.13 \\
10 & 56.23 & 75.37 & 69.72 & 22 & 201.69 & 180.43 & 225.79 \\
11 & 399.82 & 251.60 & 200.30 & 23 & 178.31 & 203.51 & 228.11 \\
\hline
\end{tabular}

Table 4. Comparison of operating costs in different scenarios.

\begin{tabular}{cccc}
\hline Scene & Scenario 1 & Scenario 2 & Scenario 3 \\
\hline Cost of electricity purchase/yuan & 10,900 & 11,518 & 4988.4 \\
Cost of gas purchase/yuan & 15,100 & 13,518 & 16,776 \\
Environmental costs/yuan & 739.8541 & 733.8270 & 594.9098 \\
Total cost/yuan & $26,740.8541$ & $25,769.827$ & $22,359.3098$ \\
\hline
\end{tabular}

Figure 12 shows a comparison of the energy change of heat storage device in different scenarios. As shown in Figure 12, energy change of heat storage device in Scenario 1 and Scenario 2 appear large fluctuations during the time interval from 7 a.m. to 16 p.m. Energy change of heat storage device in Scenario 3 is relatively flat. Figure 13 shows a comparison of produced thermal energy by gas turbine in different scenarios. It can be seen from the figure that the produced thermal energy by gas turbine in scenario 2 is less than scenario 1 and scenario 3 . This is because there are three heat sources (electric boiler, heat storage device, and CHP unit) in scenario 2, while in the other scenarios there are only two heat sources (heat storage device and CHP unit) to provide thermal energy for users. Therefore, the gas turbine of scenario 2 has less thermal energy output.

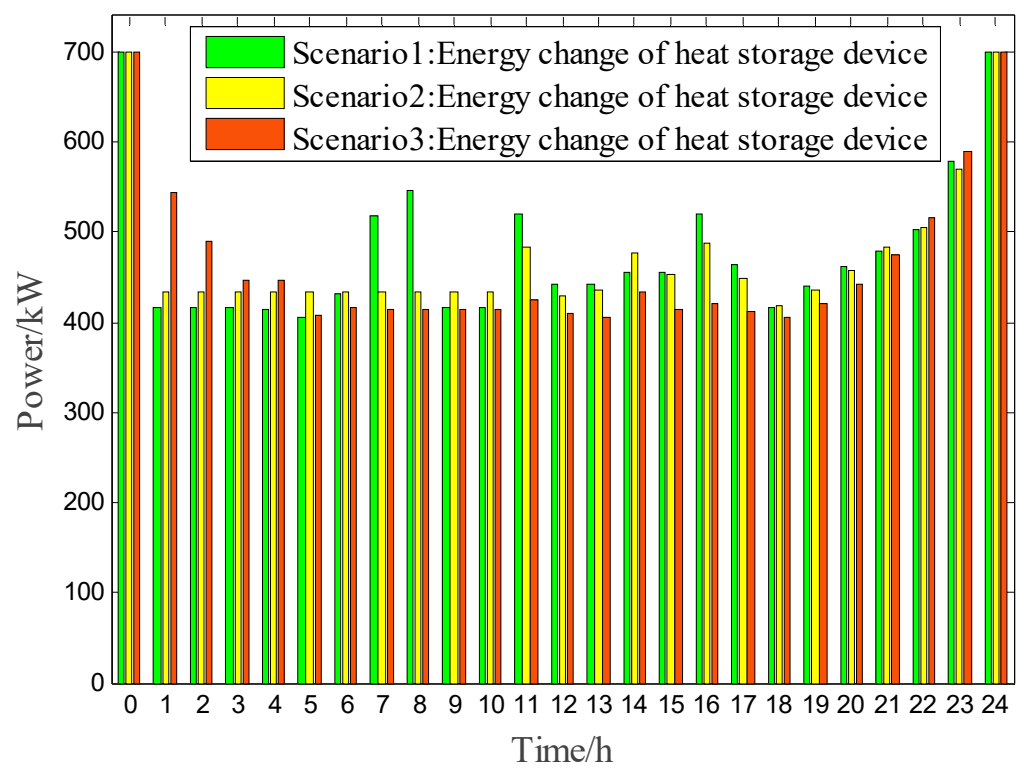

Figure 12. Energy storage changes of heat storage device in different scenarios. 


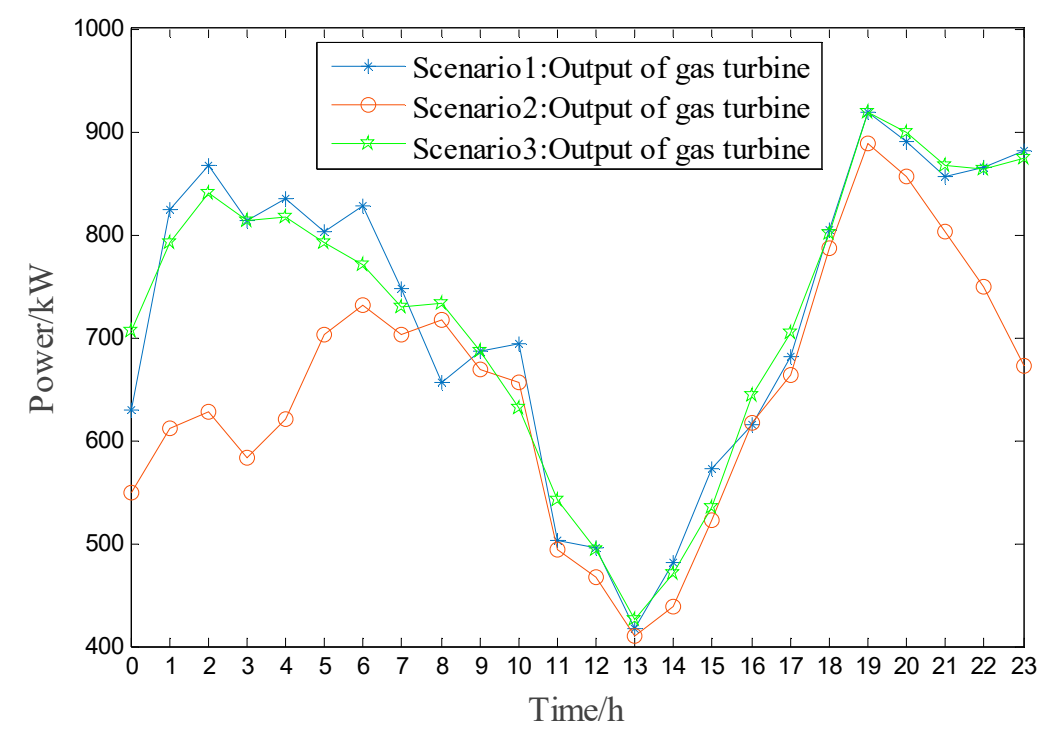

Figure 13. Output thermal energy of gas turbine in different scenarios.

Figure 14 shows the total wind power accommodation of scenario 3 (i.e., CEGBCS proposed in this paper). It can be seen from the figure that the wind power in the system is divided into two parts for accommodation. First, through coordinated optimal operation, the electric load in the system can accommodate wind power as much as possible. Then the remaining wind power, which cannot be accommodated by electric load, is used by P2G to produce natural gas.

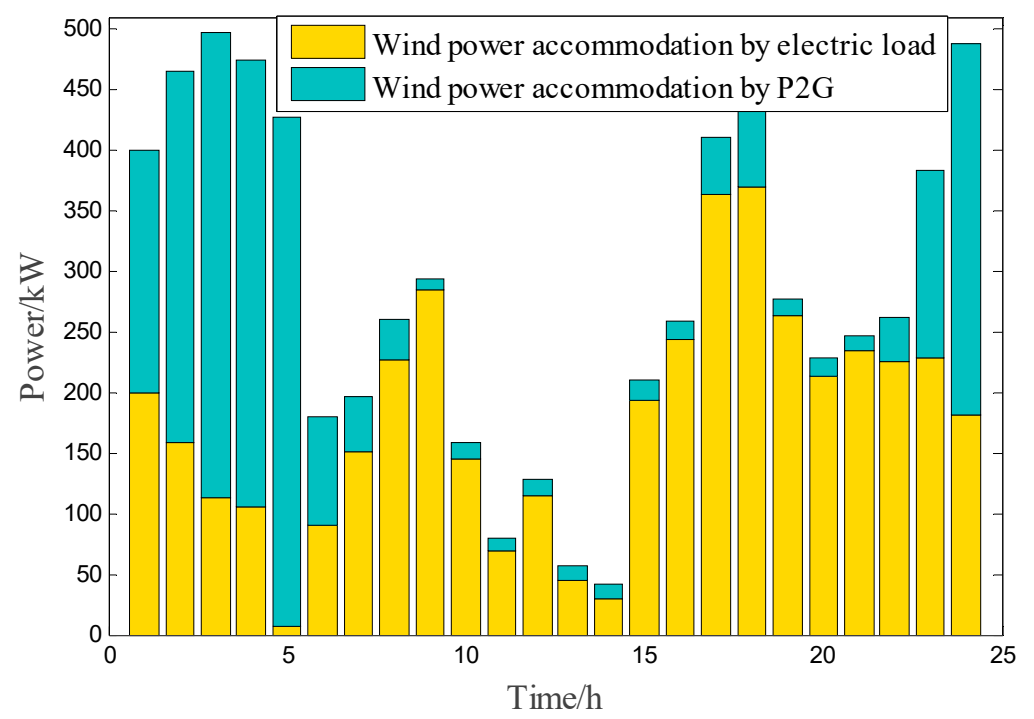

Figure 14. Overall wind power consumption of scenario 3.

Figures 15 and 16 are optimal scheduling of the heat power and electric power in scenario 3 , respectively. In this dispatch model, due to ignoring the thermal inertia, the electric power value and heat power value of each unit are equal to the electric load demand and the thermal load demand. It can be discovered from Figure 15 that during the time interval from 6 a.m. to 22 p.m., the fuel cell produces electric power to decrease the purchased electricity amount from the grid. By Figure 16, it can be discovered that most of the thermal demand in the system are met by CHP. 


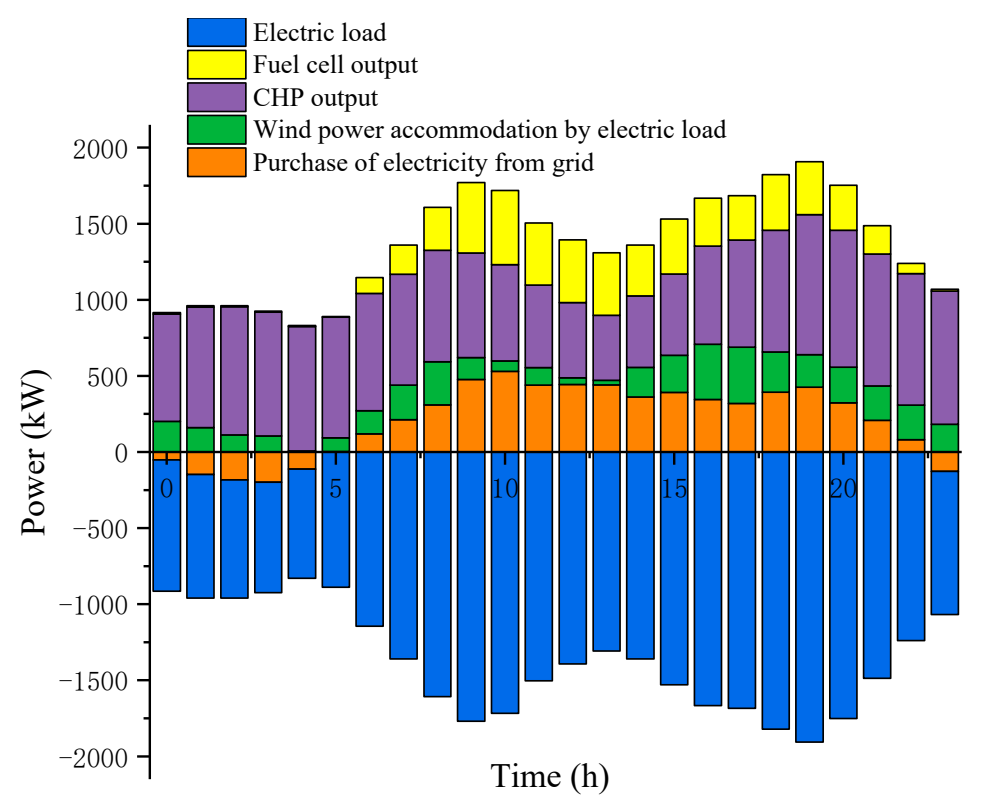

Figure 15. Electric power dispatch result of each unit in scenario 3.

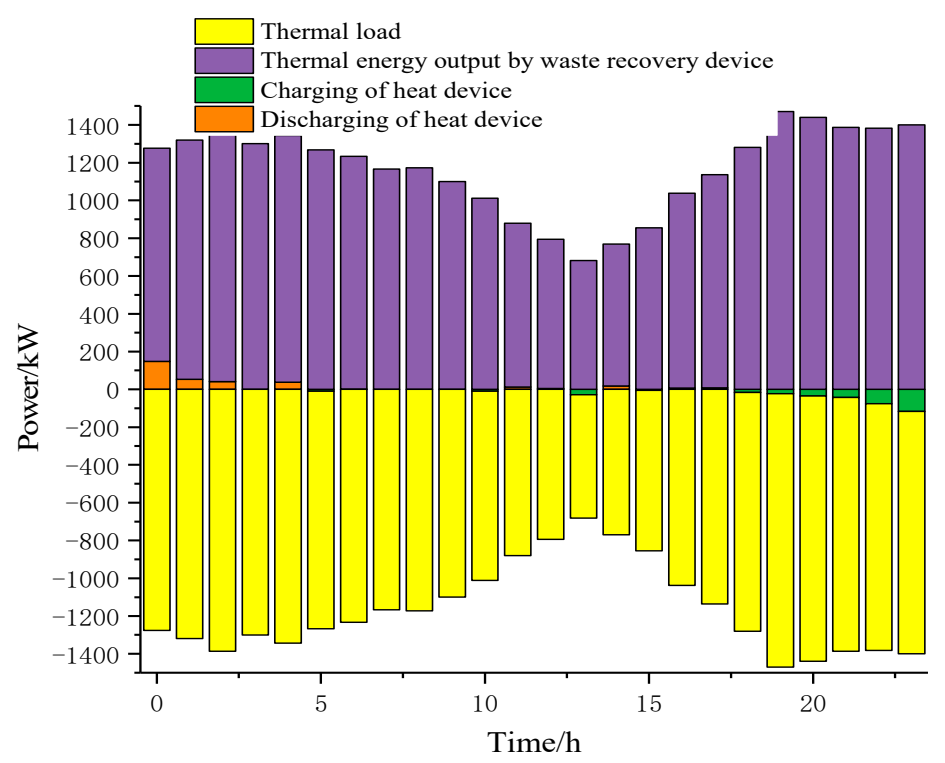

Figure 16. Optimal scheduling of heat power in scenario 3.

\section{Conclusions}

In this paper, a combined electro-gas bidirectional conversion system (CEGBCS) with P2G, fuel cell, and heat storage device is proposed. The main contribution of CEGBS is that it can effectively solve the problem of wind curtailments in northeast China during the heat supply season. Compared with the traditional method, the proposed method has the following characteristics:

1. This system can simultaneously decouple two operating modes ("Following the Electric load" and Following the Heat load) of CHP unit.

2. The CEGBS system can also realize large-scale local accommodation of wind power and long-term, low-cost indirect storage of remaining wind power.

3. The CEGBCS can realize bidirectional conversion between the electro-gas or electro-thermal energy.

4. The simulation results show that the CEGBCS proposed in this paper is not only superior to the existing methods, but also has the lowest operating cost and the best environmental benefit. 
Author Contributions: All of the authors have contributed to this research. The original ideas were provided by Y.L. The revision of the draft was guided by Z.Y. Some theoretical analysis was given by D.Y. and B.Z.

Funding: This work was supported by the National Natural Science Foundation of China (61703081), Natural Science Foundation of Liaoning Province (20170520113) and the State Key Laboratory of Alternate Electrical Power System with Renewable Energy Sources (LAPS19005).

Conflicts of Interest: The authors declare no conflict of interest.

\section{References}

1. Xue, Y.; Lei, X.; Xue, F.; Yu, C.; Dong, Z.; Wen, F.; Ju, P. A review on impacts of wind power uncertainties on power systems. Proc. CSEE 2014, 34, 5029-5040.

2. Holttinen, H.; Meibom, P.; Orths, A.; Lange, B.; O’Malley, M.; Tande, J.O.; Estanqueiro, A.; Gomez, E.; Söder, L.; Strbac, G. Impact of large amounts of wind power on design and operation of power systems, results of IEA collaboration. Wind Energy 2011, 14, 179-192. [CrossRef]

3. Liu, D.; Zhang, G.; Huang, B.; Liu, W. Optimum electric boiler capacity configuration in a regional power grid for a wind power accommodation scenario. Energies 2016, 9, 144. [CrossRef]

4. State Energy Administration Wind Power Grid Operation in the First Half of 2017. Available online: http://www.nea.gov.cn/2017-07/24/c_136468307.htm (accessed on 24 July 2017).

5. Zhang, L.; Ye, T.; Xin, Y.; Han, F.; Fan, G. Problems and measures of power grid accommodating large scale wind power. Proc. CSEE 2010, 30, 1-9.

6. Luo, X.; Wang, J.; Dooner, M.; Clarke, J. Overview of current development in electrical energy storage technologies and the application potential in power system operation. Appl. Energy 2015, 137, 511-536. [CrossRef]

7. Brekken, T.; Yokochi, A.; von Jouanne, A.; Yen, Z.Z.; Hapke, H.M.; Halamay, D.A. Optimal energy storage sizing and control for wind power applications. IEEE Trans. Sustain. Energy 2011, 2, 69-77. [CrossRef]

8. Atwa, Y.; El-Saadany, E.F. Optimal allocation of ESS in distribution systems with a high penetration of wind energy. IEEE Trans. Power Syst. 2010, 25, 1815-1822. [CrossRef]

9. Zhen, L.; Hu, W.; Lu, Q.Y.; Min, Y.; Yuan, F.; Gao, Z. Research on planning and operation model for energy storage system to optimize wind power integration. Proc. CSEE 2014, 34, 2533-2543.

10. Zheng, Y.; Dong, Z.; Luo, F.; Meng, K.; Qiu, J.; Wong, K.P. Optimal allocation of energy storage system for risk mitigation of DISCOs with high renewable penetrations. IEEE Trans. Power Syst. 2014, 29, 212-220. [CrossRef]

11. Hu, Z.; Ding, H.; Kong, T. A joint daily operational optimization model for wind power and pumped-storage plant. Autom. Electr. Power Syst. 2012, 36, 36-41.

12. Zhang, N.; Kang, C.; Kirschen, D.S.; Xia, Q.; Xi, W.; Huang, J.; Zhang, Q. Planning pumped storage capacity for wind power integration. IEEE Trans. Sustain. Energy 2013, 4, 393-401. [CrossRef]

13. Lyu, Q.; Jiang, H.; Chen, T.; Wang, H.; Lyu, Y.; Li, W. Wind power accommodation by combined heat and power plant with electric boiler and its national economic evaluation. Autom. Electr. Power Syst. 2014, 38, 6-12.

14. Li, W.; Li, T.; Wang, H.; Dong, J.; Li, Y.; Cui, D.; Ge, W.; Yang, J.; Okoye, M.O. Optimal dispatch model considering environmental cost based on combined heat and power with heat energy storage and demand response. Energies 2019, 12, 817. [CrossRef]

15. Chen, L.; Xu, F.; Wang, X.; Min, Y.; Ding, M.; Huang, P. Implementation and effect of heat storage in improving wind power accommodation. Proc. CSEE 2015, 35, 4283-4290.

16. Zhang, N.; Lu, X.; McElroy, M.; Nielsen, C.P.; Chen, X.; Deng, Y.; Kang, C. Reducing curtailment of wind electricity in China by employing electric boilers for heat and pumped hydro for energy storage. Appl. Energy 2016, 184, 987-994. [CrossRef]

17. Chen, X.; Kang, C.; O’Malley, M.; Xia, Q.; Bai, J.; Chun, L.; Sun, R.; Wang, W.; Li, H. Increasing the flexibility of combined heat and power for wind power integration in China: Modeling and implications. IEEE Trans. Power Syst. 2015, 30, 1848-1857. [CrossRef]

18. Meibom, P.; Kiviluoma, J.; Barth, R.; Brand, H.; Weber, C.; Larsen, H.V. Value of electric heat boilers and heat pumps for wind power integration. Wind Energy 2010, 10, 321-337. [CrossRef] 
19. Qadrdan, M.; Abeysekera, M.; Chaudry, M.; Wu, J.; Jenkins, N. Role of power-to-gas in an integrated gas and electricity system in Great Britain. Int. J. Hydrog. Energy 2015, 40, 5763-5775. [CrossRef]

20. Chen, Z.; Wang, D.; Jia, H.; Wang, W.; Guo, B.; Qu, B.; Fan, M. Research on optimal day-ahead economic dispatching strategy for microgrid considering P2G and multi-source energy storage system. Proc. CSEE 2017, 37, 3067-3077.

21. Yan, X.; Zhang, X.; Gu, C.; Li, F. Power to gas: Addressing renewable curtailment by converting to hydrogen. Front. Energy 2018, 12, 1-9. [CrossRef]

22. Tsupari, E.; Janne, K.; Vakkilainen, E. Economic feasibility of power-to-gas integrated with biomass fired CHP plant. J. Energy Storage 2016, 5, 62-69. [CrossRef]

23. Ursua, A.; Gandia, L.; Sanchis, P. Hydrogen production from water electrolysis: Current status and future trends. Proc. IEEE 2012, 100, 410-426. [CrossRef]

24. Belderbos, A.; Delarue, E.; D'Haeseleer, W. Possible role of power-to-gas in future energy systems. In Proceedings of the 12th International Conference on the European Energy Market (EEM), Lisbon, Portugal, 19-22 May 2015.

25. Li, Y.; Liu, W.; Zhao, J. Optimal dispatch of combined electricity-gas-heat energy systems with power-to-gas devices and benefit analysis of wind power accommodation. Power Syst. Technol. 2016, 40, 3680-3689.

26. Wu, G. Current challenge and perspective of PGM-free cathode catalysts for PEM fuel cells. Front. Energy 2017, 11, 286-298. [CrossRef]

27. Pandian, M. Efficiency and economics analysis of proton exchange membrane fuel cell. In Proceedings of the 2010 Conference Proceedings IPEC, Singapore, 27-29 October 2011.

28. Zhang, J.; Cao, P.; Xu, L.; Wang, Y. Modeling nanostructured catalyst layer in PEMFC and catalyst utilization. Front. Chem. Sci. Eng. 2011, 5, 297-302. [CrossRef]

29. Morteza, N.; Saeed, A. Optimal economic dispatch of FC-CHP based heat and power micro-grids. Appl. Eng. 2017, 114, 756-769.

30. Pijarski, P.; Wvdra, M.; Kacejko, P. Optimal control of wind power generation. Adv. Sci. Technol. 2018, 12, 9-18. [CrossRef]

31. Sun, Q.; Zhang, N.; You, S. The Dual Control with Consideration of Security Operation and Economic Efficiency for Energy Hub. IEEE Trans. Smart Grid 2019, 14, 1-12. [CrossRef]

32. Shahbaz, H.; Mohammed, A.; Salman, K.; Hussain, A.; Saqib, M.A. Implementation and comparison of particle swarm optimization and genetic algorithm techniques in combined economic emission dispatch of an independent power Plant. Energies 2019, 12, 2037.

33. Yazdani, A.; Jayabarathi, T.; Ramesh, V.; Raghunathan, T. Combined heat and power economic dispatch problem using firefly algorithm. Front. Energy 2013, 7, 133-139. [CrossRef]

34. Wu, X.; Wang, X.; Wang, J.; Bie, Z. Economic generation scheduling of a microgrid using mixed integer programming. Proc. CSEE 2013, 33, 1-9. 